\title{
Controlling Calcium Sulphate Scale Formation In Acid Mine Waters.
}

\author{
Max Fazel, Stephen P. Chesters, Gregory Gibson \\ Genesys International Ltd. UK \\ 3A Aston Way, Middlewich, Cheshire, CW10 0HS UK
}

\begin{abstract}
Membrane technologies are capable of treating mine waste waters to produce clean permeate water for reuse and a concentrate stream that can be used for valuable metals recovery. Reverse Osmosis (RO), Nano-filtration (NF) and Ultra-filtration (UF) technology is increasingly being adopted. In precious metal mines, waste water can be concentrated using membrane plant so additional metals can be recovered from barren liquor. Acid mine drainage (AMD) is increasingly treated and then reused or sent off site as a valuable resource for domestic and agricultural use. The use of membrane technology is hampered by the potential for rapid membrane fouling and calcium sulphate (gypsum) scale deposition. The authors have embarked on research project to investigate calcium sulphate scale formation in acidic $\mathrm{pH}$ and in the presence of a variety of soluble metals. New antiscalant chemistry for preventing sulphate scale formation in acidic conditions with metals have been investigated and the results are presented.

A series of experiments were performed to assess calcium sulphate scale formation and inhibition in the presence of metals at low $\mathrm{pH}$. The dissociation of sulphate and bi-sulphate ions at low $\mathrm{pH}$ was investigated, followed by Threshold jar tests to screen water chemistries at different conditions and finally using actual membrane coupons with a Flat Sheet Test rig to assess membrane performance and scaling inhibition.
\end{abstract}

Keywords: Membranes, Antiscalant, Gypsum scale, Threshold test, Metals, AMD.

\section{Introduction}

One of the most common scales encountered in AMD type waters used for metal recovery or processing is gypsum $\left(\mathrm{CaSO}_{4} \cdot 2 \mathrm{H}_{2} \mathrm{O}\right)$. The use of membranes is increasingly being adopted for treatment of these waters, however, there is potential for rapid fouling and scaling if the right antisclants are not used to prevent crystallization. Furthermore, the scaling problem is complicated by the presence of metal ions like $\mathrm{Fe}$ and $\mathrm{Al}$ and impurities which may render the traditional antiscalant to become ineffective ${ }^{5,6}$. A series of experiments were performed to assess calcium sulphate scale formation and inhibition in the presence of metals at low $\mathrm{pH}$. The dissociation of sulphate and bi-sulphate ions at low $\mathrm{pH}$ was investigated, followed by Threshold jar tests to screen water chemistries at different conditions and finally using actual membrane coupons with a Flat Sheet Test rig to assess membrane performance and scaling inhibition.

\section{Dissociation of Sulphate and Bi-sulphate at low pH}

Low $\mathrm{pH}$ mine waters (AMD) typically have a $\mathrm{pH}$ of 1 to 3, our research studies found that at such low $\mathrm{pH}$ normal scale inhibitors chemistries like phosphonates and polycarboxylates are ineffective. The chemistry of sulphuric acid speciation shows that at $\mathrm{pH}<1$ the sulphuric acid dissociates mainly as the bisulphate ion $\left(\mathrm{HSO}_{4}^{-}\right)^{1}$. Other species are formed at various pHs: $\mathrm{HSO}_{4}{ }^{-}, \mathrm{H}^{+}$and $\mathrm{SO}_{4}{ }^{2-}$. The problem is further complicated by the presence of metal ions like $\mathrm{Fe}$ and $\mathrm{Al}$ etc which can have a further negative impact on scale inhibitor performance ${ }^{5,6}$.

The sulphuric acid molecule has two Hydrogen atoms (protons) and can therefore donate one proton to form $\mathrm{HSO}_{4}{ }^{-}$or both of them to form $\mathrm{SO}_{4}{ }^{2-}$. The loss of the two protons is dependent upon $\mathrm{pH}$. The Dissociation constant (Ka) gives the strength of an acid in solution.

The first dissociation of Sulphuric Acid is complete (Strong Acid)

$\mathrm{H}_{2} \mathrm{SO}_{4} \longrightarrow \mathrm{H}^{+}(\mathrm{aq})+\mathrm{HSO}_{4}^{-}(\mathrm{aq}) \quad \mathrm{Ka} 1=$ Very large $(\mathrm{pH}<1)$

The $2^{\text {nd }}$ dissociation of Sulphuric Acid is not complete (Weak Acid)

$\mathrm{HSO}_{4}{ }^{-} \longrightarrow \mathrm{H}^{+}(\mathrm{aq})+\mathrm{SO}_{4}{ }^{2-}(\mathrm{aq}) \quad \mathrm{Ka} 2=1.2 \times 10^{-2}$ (or $\left.\mathrm{pH} 1.9\right)$ 
At $\mathrm{pH}$ 0-1 the dominant species is $\mathrm{HSO}_{4}$

At $\mathrm{pH} 2$ there is $\sim 50 \%$ each of $\mathrm{HSO}_{4}{ }^{-}$and $\mathrm{SO}_{4}{ }^{2-}$

At $\mathrm{pH}>4$ the dominant species is $\mathrm{SO}_{4}{ }^{2-}$

The dissociation or speciation of sulphuric acid was demonstrated by FTIR spectroscopy. The below spectra show the peaks of the relative $\mathrm{SO}_{4}{ }^{2-}, \mathrm{HSO}_{4}{ }^{-}$ions when sodium sulphate was dissolved at $\mathrm{pH} 1$ and 8.

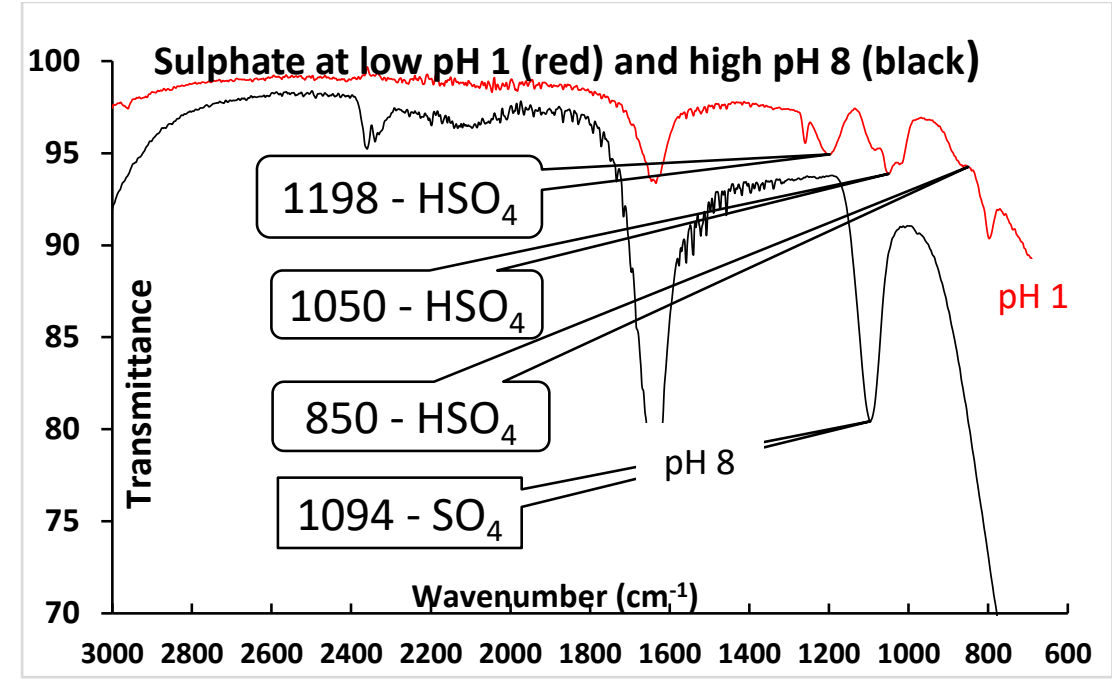

Fig. 1: Sulphate species at different $\mathrm{pH}(\mathrm{Red}-\mathrm{pH} 1$, Black $-\mathrm{pH} 8)$

The spectra show that at $\mathrm{pH} 8$ the sulphate peak was at $1094 \mathrm{~cm}^{-1}$ and at $\mathrm{pH} 1$ additional peaks at 1198, 1050 and 850 $\mathrm{cm}^{-1}$ can be seen, which are attributed to the $\mathrm{HSO}_{4}^{-}$bisulphate ion ${ }^{7}$ (also notice the absence of the 1094 peak for $\mathrm{pH} 1$ ).

\subsection{Antiscalant formulation for $\mathrm{CaSO}_{4}$ Scale in AMD water}

Calcium sulphate is a strongly crystalline salt that develops through weak needle and platelet forms to highly stable rosettes particularly in low flow areas in the membrane feed spacer.,

It has been theorised by Darton ${ }^{4}$ that in the case of 'threshold inhibitors' used in laboratory studies in standard threshold tests, the more antiscalant added to the water the longer the time to the onset of precipitation. In all cases some minor precipitation occurs and this eventually leads to 'catastrophic precipitation' where the precipitating salt reaches equilibrium and there is no enhanced solubility at all. Eventually all threshold performance is lost, irrespective of the treatment levels used.

Antiscalants are considered to inhibit crystal growth by adsorbing onto reactive (nucleation) sites ${ }^{3,8}$. Most traditional antiscalants are phosphonate and/or polycarboxylic based and as the $\mathrm{pH}$ is decreased their performance is less effective against gypsum scale formation. ${ }^{10}$ This is due to protonation of the phosphonate functional groups at lower $\mathrm{pH}\left(-\mathrm{PO}_{3} \mathrm{H}_{2}\right)$ resulting in less adsorption to nucleation sites (hence increased crystal growth). It is reported by Weijnen and Rosmalen ${ }^{11}$ that at low $\mathrm{pH}(<3)$, the phosphonic acid groups remain protonated and the phosphonate inhibitor performance is nil. At higher $\mathrm{pH}>4$ the inhibitors with phosphonic, carboxylic or sulfonic acid groups become disassociated (eg. $\mathrm{PO}_{3}{ }^{2-}$ ) and show increasing inhibition with increasing $\mathrm{pH}$.

Consideration of these laboratory phenomena enabled combinations of threshold inhibitors, crystal distortion and dispersion agents to be used in a formulation to build a more effective calcium sulphate antiscalant.

A series of Threshold inhibition jar tests were designed and conducted to screen potential antiscalants at various conditions for $\mathrm{pH}, \mathrm{Ca}, \mathrm{SO}_{4}$ and metal ion concentrations to see if an improved performance could be observed. 


\section{Threshold Jar Tests}

Tests carried out with:

- Antiscalants Genesys CAS, CS2 and AS-26

- $\mathrm{pH} 1$ to 7, Temp: Ambient, 24hrs static jar test

- $\mathrm{Ca}=2000 \mathrm{ppm}, \mathrm{SO}_{4}=20,000 \mathrm{ppm}\left(\mathrm{CaSO}_{4}\right.$ saturation x7.5)

- Metals: Various - Fe, Cu, Al, Mn and $\mathrm{Zn}$ (0 to 300ppm)

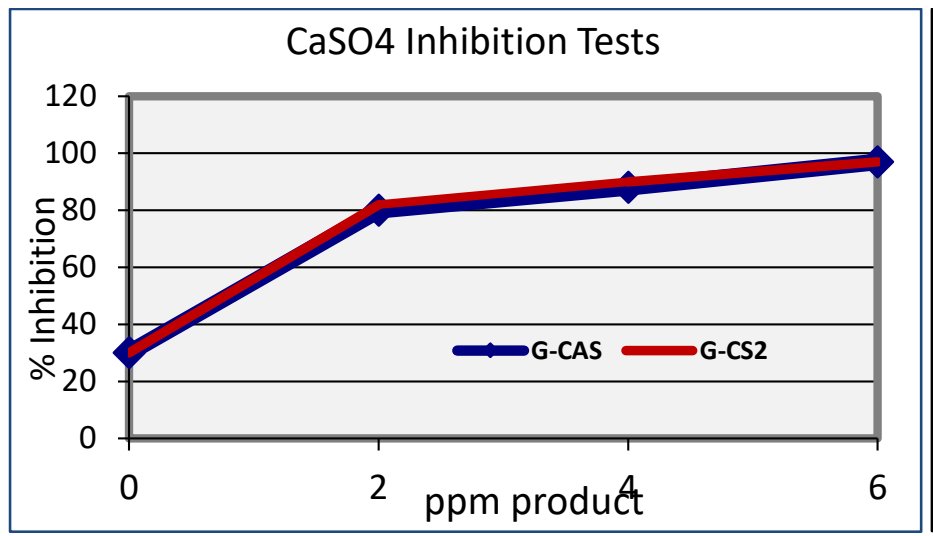

Fig. 2: Calcium sulphate inhibition tests, $\mathrm{pH} 7,24 \mathrm{hr}$, $\mathrm{CaSO}_{4}$ saturation x7.5.

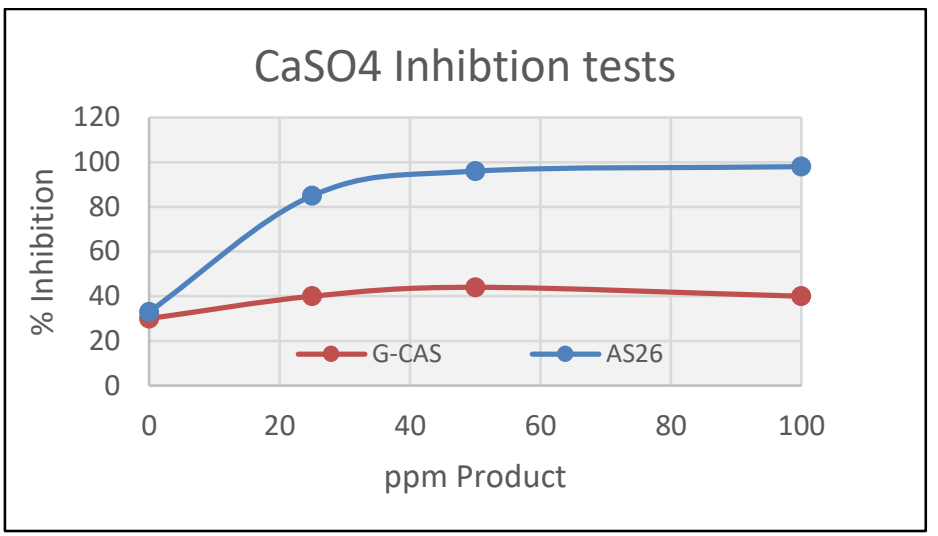

Fig. 3: Calcium sulphate inhibition tests, $\mathrm{pH} \mathrm{2,} \mathrm{24hr,}$ $\mathrm{CaSO}_{4}$ saturation x7.5.

As can be seen in the above graphs 2 and 3 and the jar test photos, antiscalants G-CAS and G-CS2 were able to prevent $\mathrm{CaSO}_{4}$ scale formation for waters of saturation index value $\mathrm{SI}_{\mathrm{CaSO} 4} \sim 7.5$ at neutral $\mathrm{pH}$. However, the same inhibitors did not prevent scale formation at low $\mathrm{pH}$, but our newly developed inhibitor, AS-26, especially for AMD waters was able to give near $100 \%$ inhibition.

The next set of tests were to determine what effect the presence of metals had on the antiscalant's ability to control $\mathrm{CaSO}_{4}$ scaling in these AMD type waters.

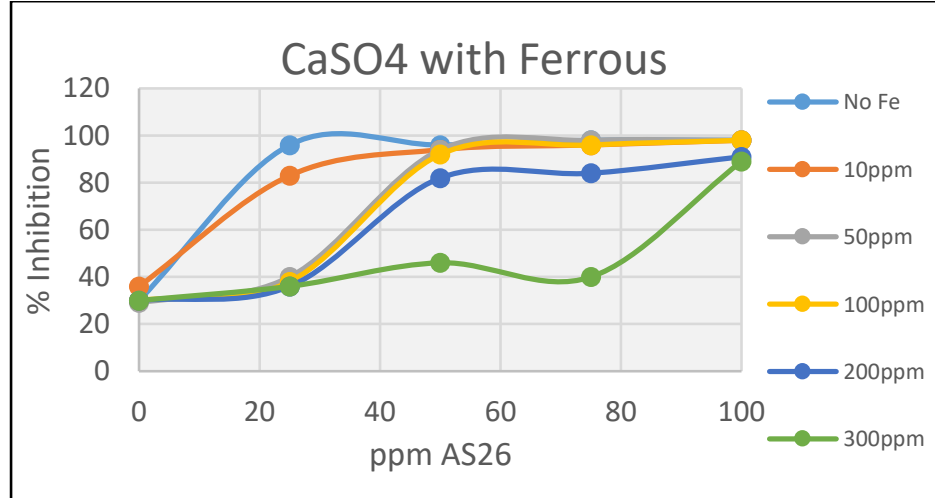

Fig. 4: Calcium sulphate inhibition with Ferrous iron, pH 2, 24hr.

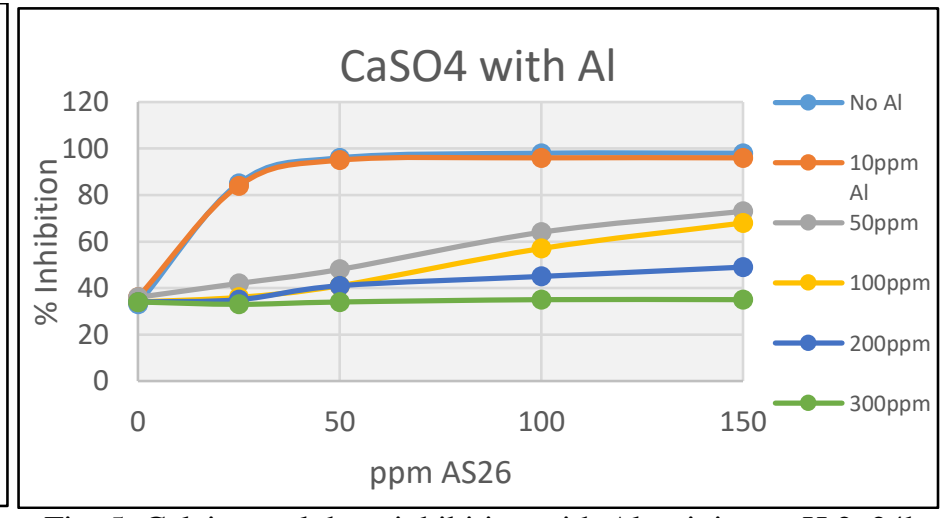

Fig. 5: Calcium sulphate inhibition with Aluminium, $\mathrm{pH}$ 2, 24hr.

The above graphs Fig 4 and 5 shows that with increasing levels of iron and aluminium required a corresponding increase in antiscalant dose. Ie, the presence of these metals, Aluminium more so than Iron, had a detrimental effect on the antisclant's performance. 


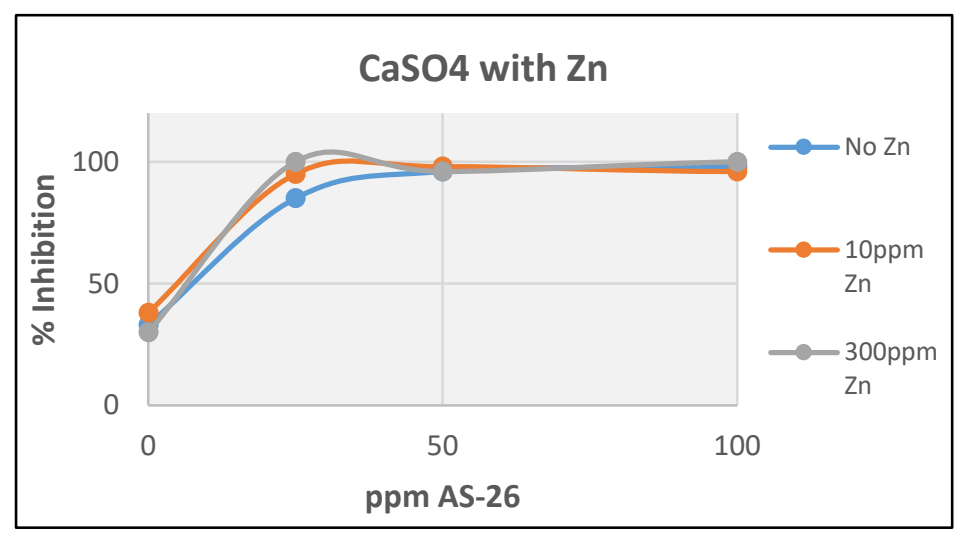

Fig. 6: Calcium sulphate inhibition with Ferrous iron, $\mathrm{pH}$ 2, 24hr.

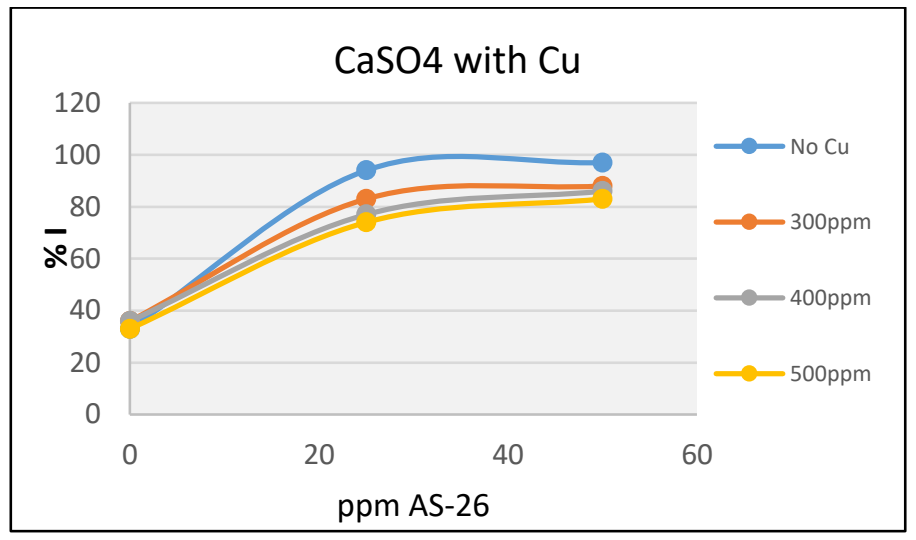

Fig. 7: Calcium sulphate inhibition with Zinc, $\mathrm{pH} 2,24 \mathrm{hr}$.

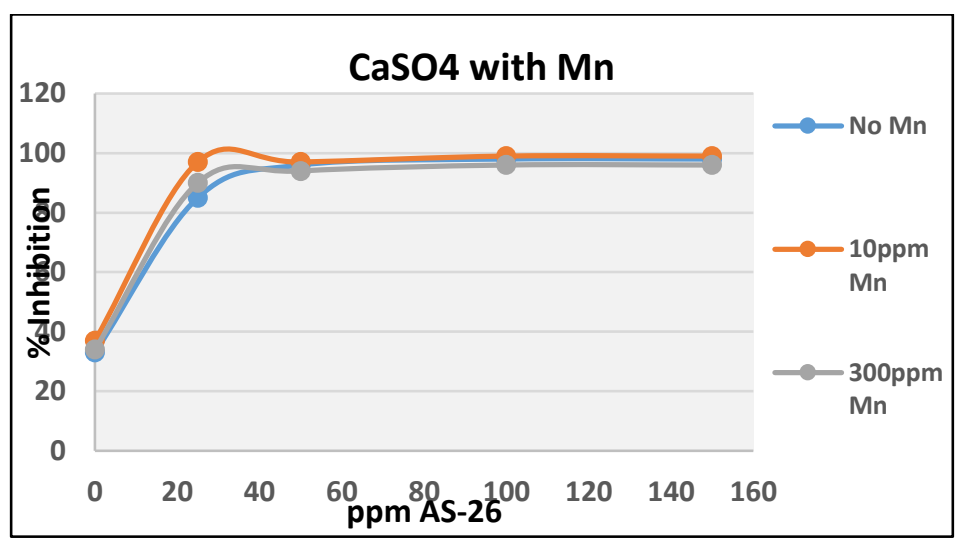

Fig. 8: Calcium sulphate inhibition with Manganese, $\mathrm{pH}$ 2, $24 \mathrm{hr}$.

The above graphs Fig 6,7 and 8 shows that the presence of copper (and even less so for zinc and manganese) were not as detrimental on the aniscalant's ability to control $\mathrm{CaSO}_{4}$ scaling.

\subsection{Threshold Jar test photos}

Tests carried out with:

Antiscalants Genesys CAS, CS2 and AS-26; $\mathrm{pH} 1$ to 7; Temp: Ambient, 24hrs static jar test

$\mathrm{Ca}=2000$ ppm, $\mathrm{SO} 4=20,000$ ppm $(\mathrm{SI}$ CaSO4 7.5); Metals: Various $-\mathrm{Fe}$ and $\mathrm{Al}$ 


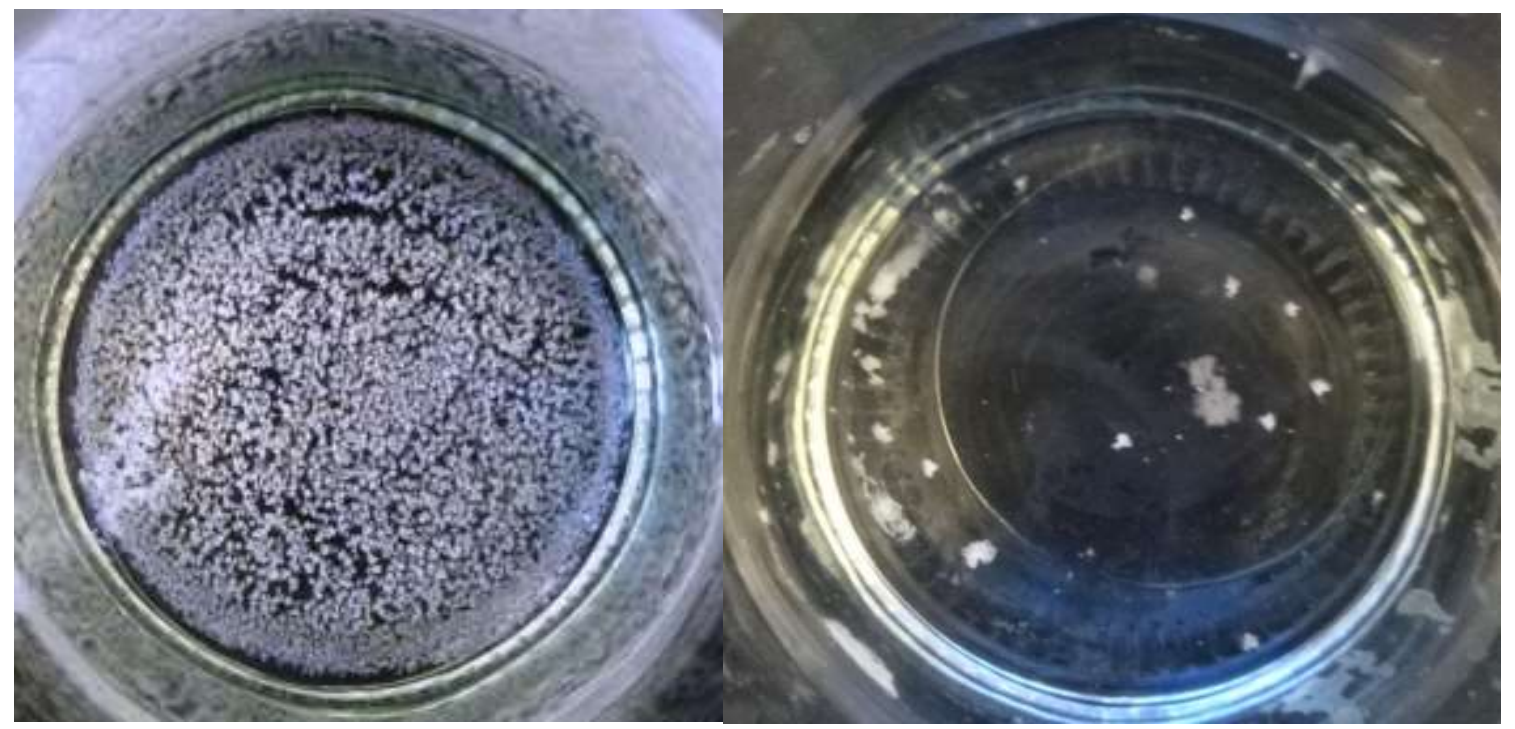

Fig. 9: Blank.

Fig. 10: 2ppm G-CAS.

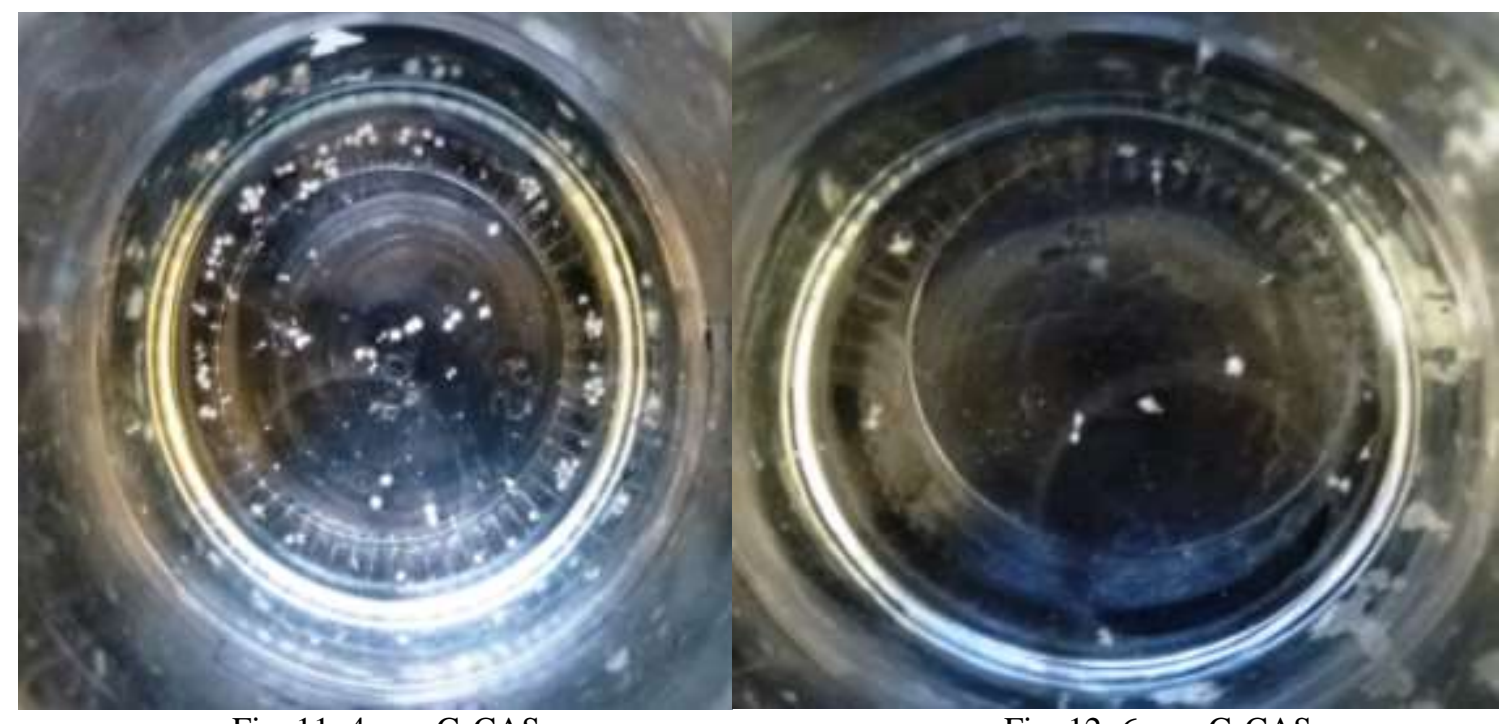

Fig. 11: 4ppm G-CAS.

Fig. 12: 6ppm G-CAS. 


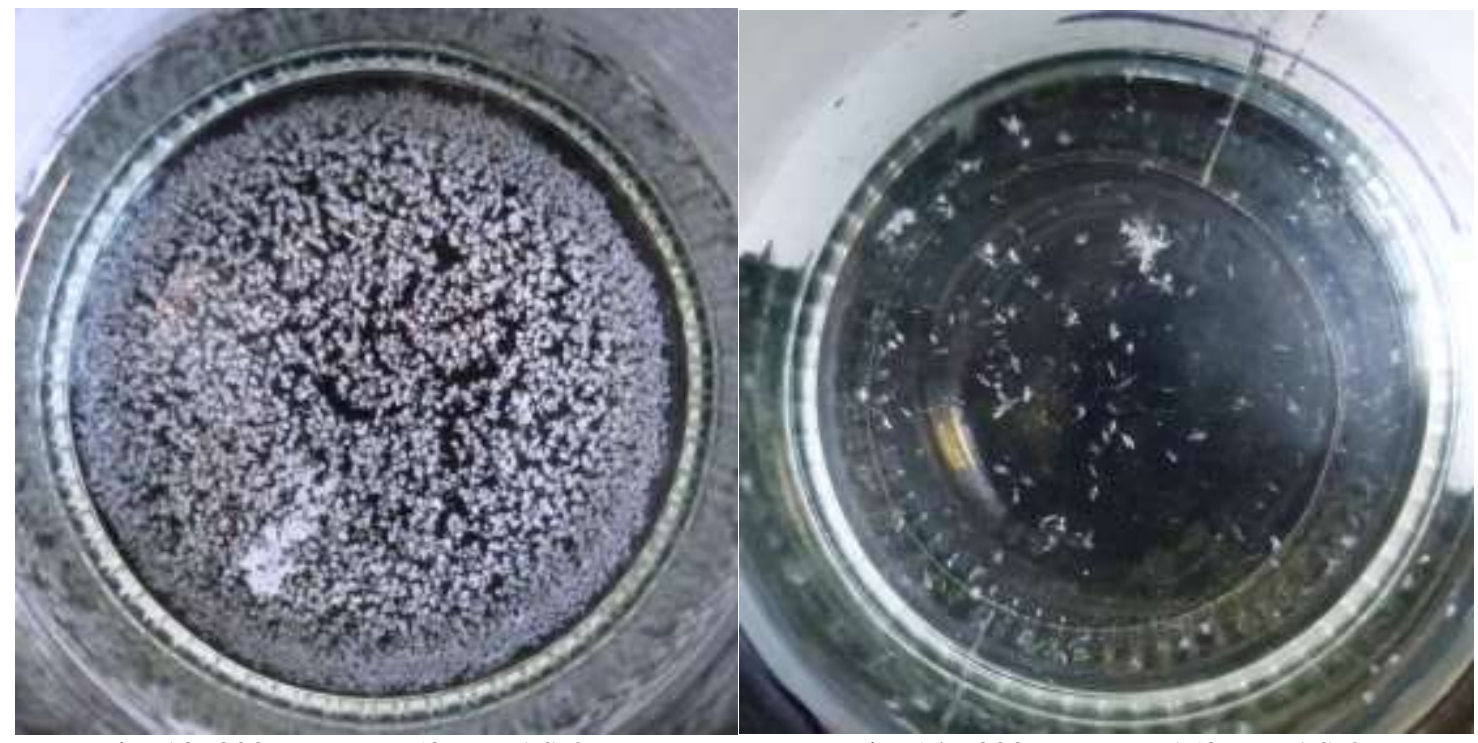

Fig. 13: 300ppm Fe + 50ppm AS-26.

Fig. 14: 300ppm Fe + 150ppm AS-26.

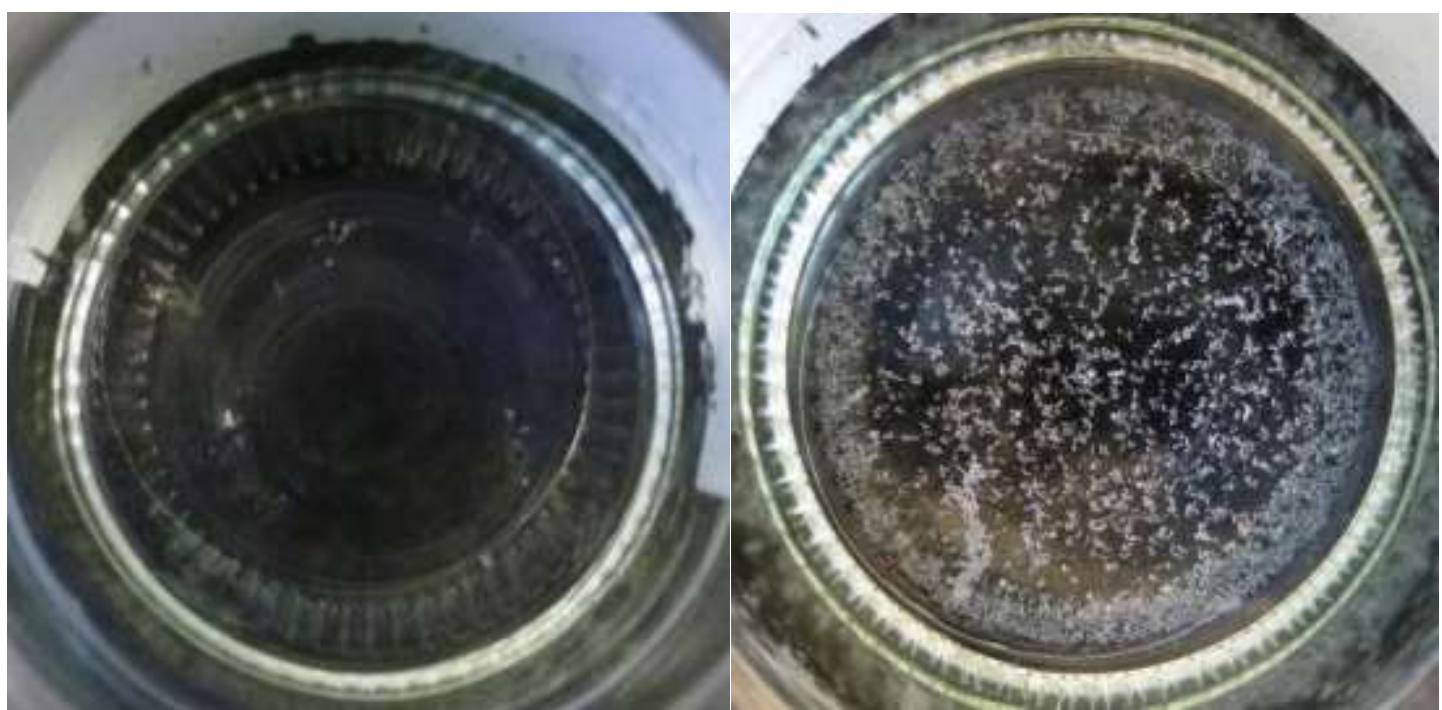

Fig. 15: 300ppm Fe + 300ppm AS-26.

Fig. 16: 300ppm Al + 150ppm AS-26.

\subsection{Discussion}

The above graphs and jar test photos clearly show the negative impact metals like Fe and $\mathrm{Al}$ have on the antiscalant's ability to function. Figure 1 shows that our traditional antiscalants, G-CAS and G-CS2 were able to control CaSO $\mathrm{Scaling}$ at $\mathrm{pH} 7$ with only $6 \mathrm{ppm}$ dose. However, Figure 2 shows that at low $\mathrm{pH}$ and without any metals with a $\mathrm{CaSO}_{4} \mathrm{SI}_{2} 7.6$, required $50 \mathrm{ppm}$ of inhibitor AS-26 to give near 100\% inhibition, whereas, our "traditional" antiscalant was not able to control scaling at this low $\mathrm{pH}$ even at very high dose rates of $150 \mathrm{ppm}$. The antiscalant's performance in the presence of iron can be seen in Figure 3, a corresponding increase in dose rate is needed for increasing levels of iron. Likewise, Figure 4 shows the effect Aluminium has on the dose rate, requiring even higher dose rates compared to iron. Notice that 300ppm of iron required $100 \mathrm{ppm}$ of AS-26, whereas, $150 \mathrm{ppm}$ of AS-26 was not able to control $\mathrm{CaSO}_{4}$ scaling in the presence of $300 \mathrm{ppm} \mathrm{Al}$ and the presence of even 10ppm Al only gave $70 \%$ inhibition with 150ppm AS-26. 
The other graphs (Graphs 5 to 7) show that the presence of copper (and even less so for zinc and manganese) were not as detrimental on the aniscalant's ability to control $\mathrm{CaSO}_{4}$ scaling.

It was also observed with the Threshold jar tests that at lower $\mathrm{pH}$, the rate of $\mathrm{CaSO}_{4}$ precipitation was accelerated in the absence of inhibitors, ie, the crystal growth within the jars occurred quicker than at neutral $\mathrm{pH}$. This can be explained by the increased $\mathrm{HSO}^{-}$species as opposed to $\mathrm{SO}^{2-}$ at lower $\mathrm{pH}$ gives rise to increased gypsum precipitation.

\section{Flat Sheet Membrane Tests}

Test conditions:

- Antiscalant Genesys AS26

- $\quad \mathrm{pH}$, Temp: Ambient, 2 hrs circulation

- $\mathrm{Ca}=2000 \mathrm{ppm}, \mathrm{SO}_{4}=5000 \mathrm{ppm}\left(\mathrm{SI} \mathrm{CaSO}_{4} \sim 3\right)$

- Metals: Fe (0 to 300ppm)

- Standard BW30 membrane $\left(133 \mathrm{~cm}^{2}\right)$ operated at 15 bar

The testing procedure involves using a Flat Sheet Test Rig and virgin membrane and spacer coupons. The tests involve recirculation of a saturated solution of calcium sulphate (and iron) with and without the antiscalant chemical and monitoring the performance of the membrane (flux and salt rejection) over the test period.

The membrane and spacer are also examined after the test for signs of scale deposition.

\subsection{Flat Sheet Results: No inhibitor (blank)}

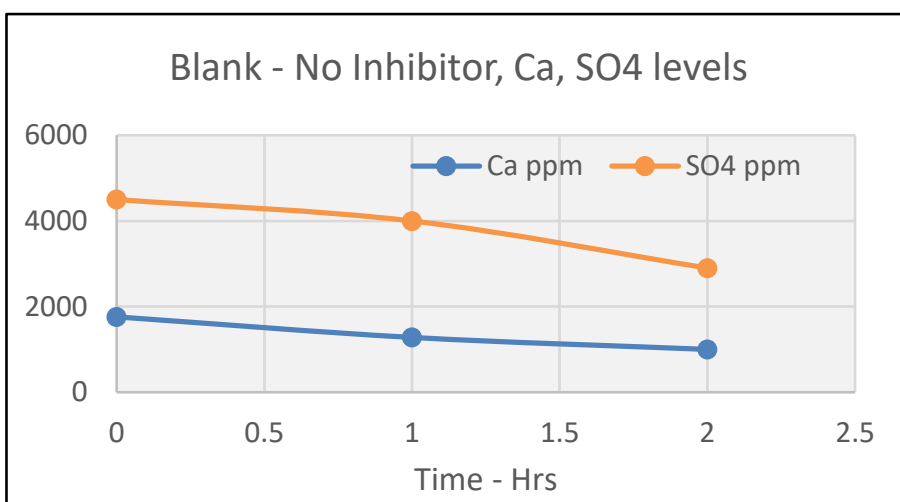

Fig. 17: Calcium and sulphate levels - no inhibitor test, pH 3.

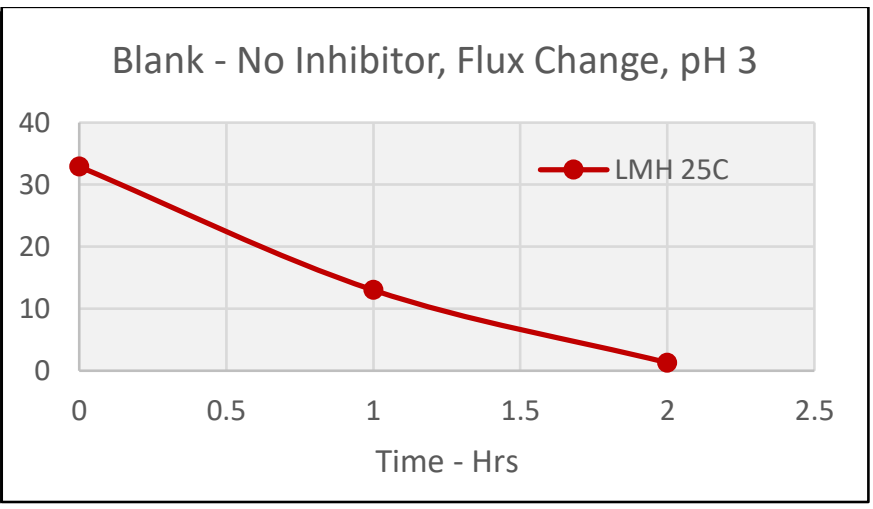

Fig. 18: Flux change - with no inhibitor test, $\mathrm{pH} 3$.

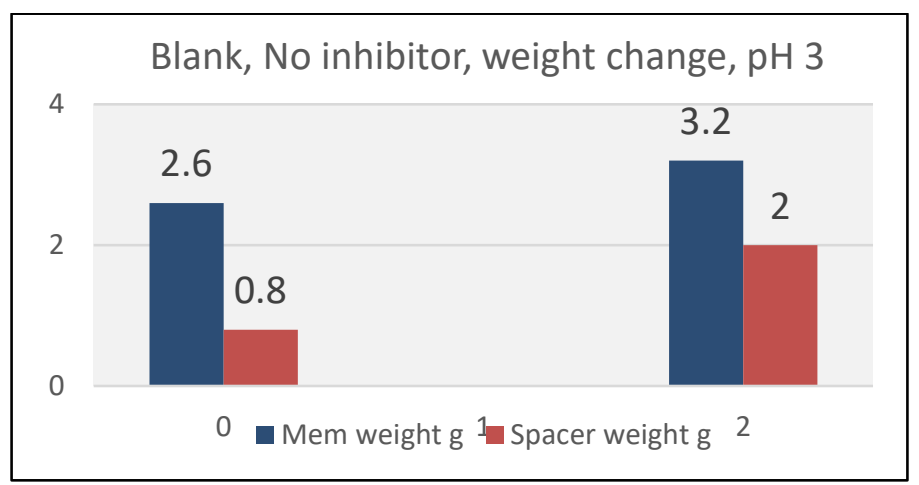

Fig. 19: Membrane and spacer weight change - no inhibitor test, $\mathrm{pH} 3$. 


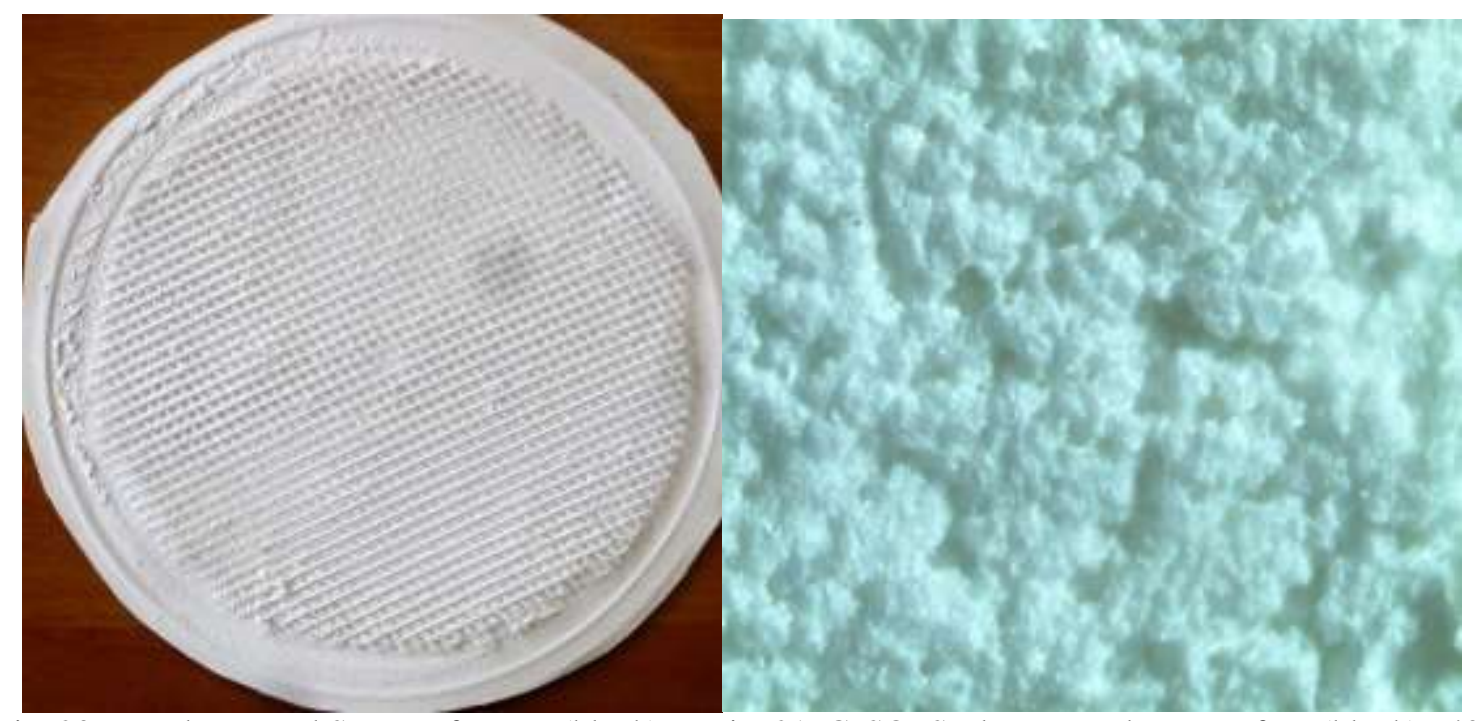

Fig. 20: Membrane and Spacer after test (blank). Fig. 21: $\mathrm{CaSO}_{4}$ Scale on membrane surface (blank) x40.

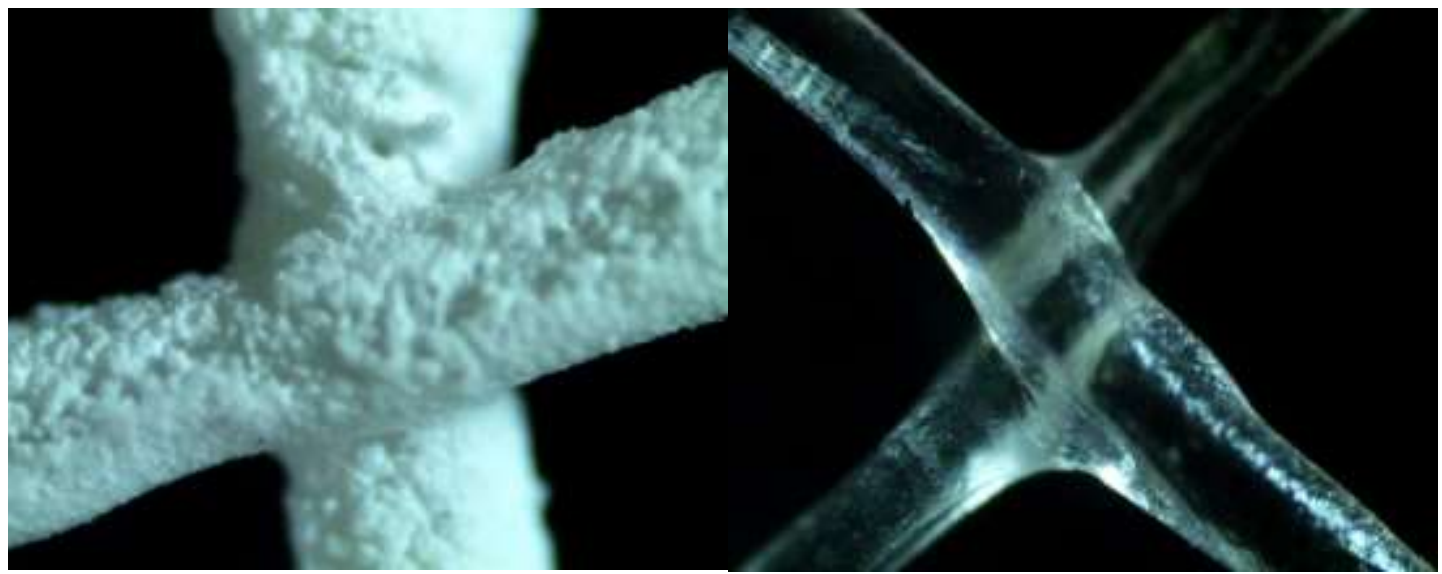

Fig. 22: Scale on Spacer filament (blank) x40. $\quad$ Fig. 23: Clean Spacer before blank test x40.

\subsection{Flat Sheet Results: With Inhibitor}

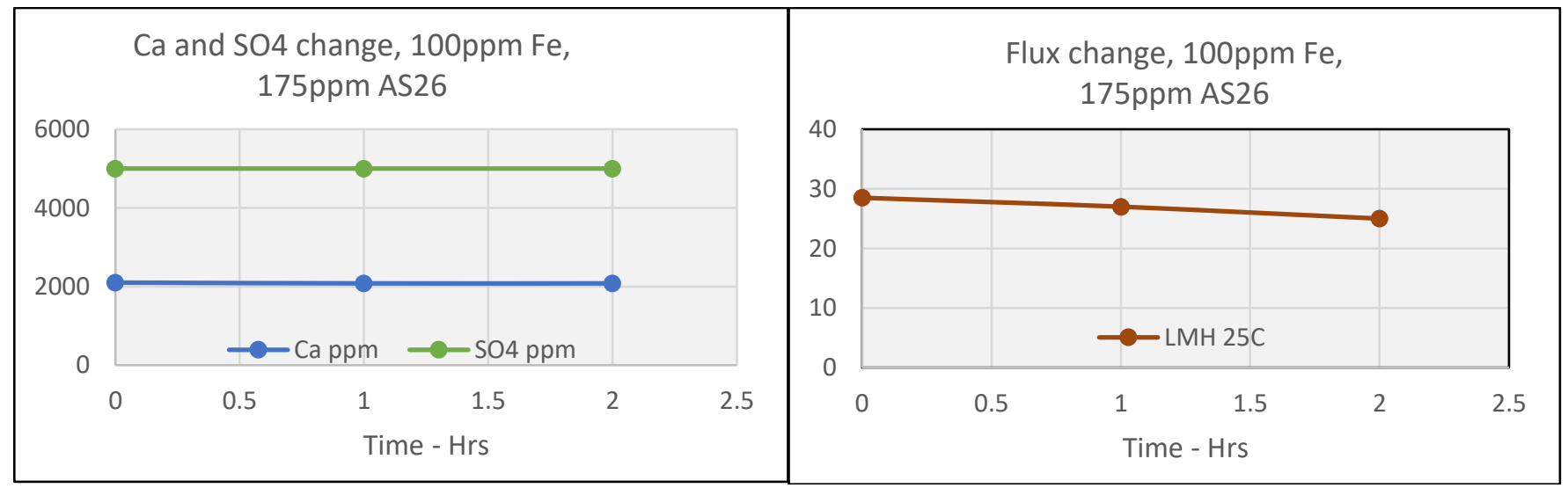

Fig. 24: Calcium and sulphate levels - with inhibitor test, $\mathrm{pH} 3$. Fig. 25: Flux performance - with inhibitor test, $\mathrm{pH} 3$. 


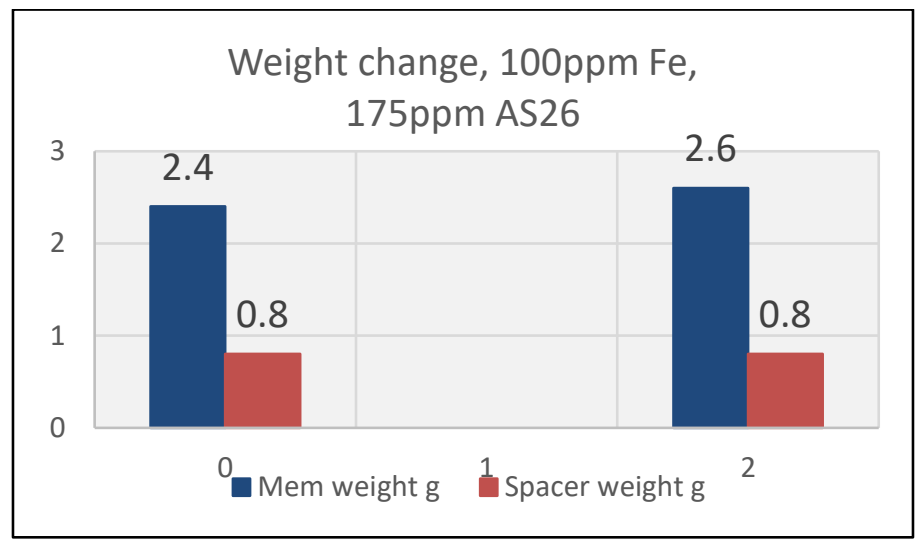

Fig. 26: Membrane and spacer weight change - with inhibitor test, $\mathrm{pH} 3$.

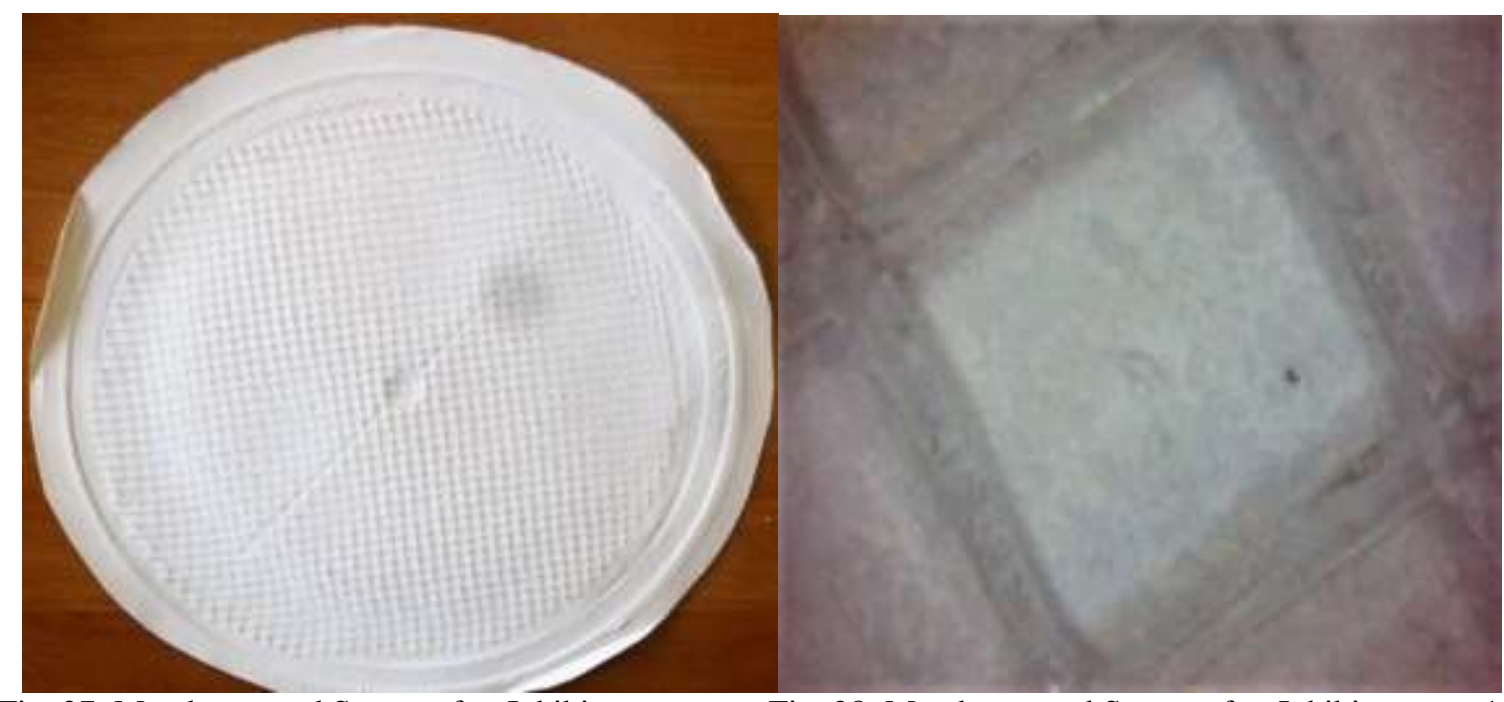

Fig. 27: Membrane and Spacer after Inhibitor.

Fig. 28: Membrane and Spacer after Inhibitor test x10.

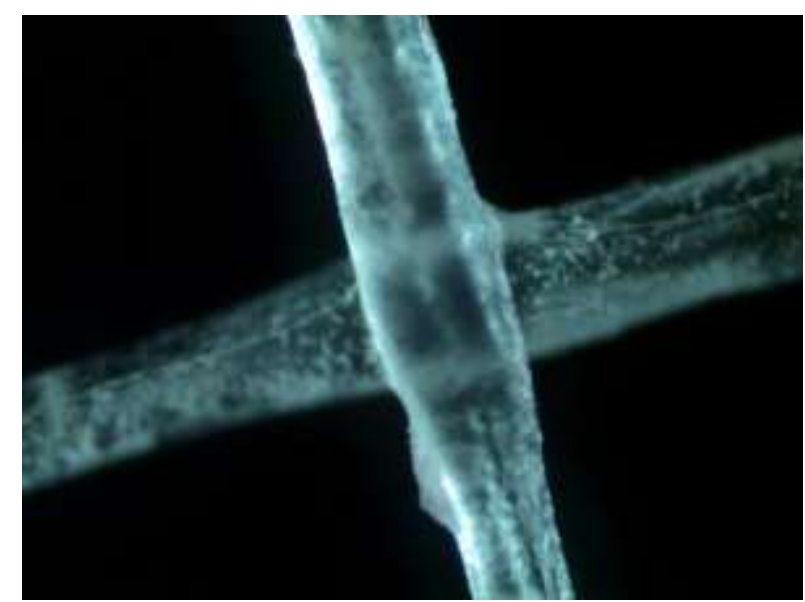

Fig. 29: Spacer filament after Inhibitor test x40. 


\subsection{Discussion}

The Flat sheet tests show that in the absence of inhibitor both the membrane and spacer scaled, with the majority of the scale being on the spacer material (Fig 19-23). Fig 18 shows that the flux decline with no inhibitor was dramatic over the 2 hour test period due to scaling.

Figs 24-29 show the effect of $175 \mathrm{ppm}$ of inhibitor AS26 with $100 \mathrm{ppm} \mathrm{Fe} \mathrm{Fe}^{2+}$ had in controlling scale formation. The flux rate was only marginally reduced and no scale was detected on both membrane and spacer after the test. A comparison of Figs 21 and 22 (without inhibitor) and Figs 28 and 29 (with inhibitor) clearly demonstrate the effectiveness of scale control with AS26.

\section{Conclusion}

Traditional phosphonate and polcarboxylate type antiscalants are able to control $\mathrm{CaSO}_{4}$ scaling by retarding crystal growth in supersaturated brine solutions at normal $\mathrm{RO}$ operating $\mathrm{pH}$ of $\sim 5-10$ at relatively low doses. However, at low $\mathrm{pH}$ $(<4)$ and even without the presence any metals, these existing inhibitors do not work due to the functional groups of these inhibitors remaining protonated (undissociated).

At low $\mathrm{pH}$, the rate of $\mathrm{CaSO}_{4}$ precipitation was accelerated in the absence of inhibitors, ie, the crystal growth within the jars tests occurred quicker than at neutral $\mathrm{pH}$, due to increased $\mathrm{HSO}_{4}{ }^{-}$species as opposed to $\mathrm{SO}_{4}{ }^{2-}$ levels.

At low pH $(<4)$, with a $\mathrm{CaSO}_{4}$ SI $\sim 7.6$, a new antiscalant AS-26 gave almost $100 \%$ inhibition. The antiscalant's performance in the presence of iron and aluminium had a dramatic detrimental effect on the aniscalant's ability to control $\mathrm{CaSO}_{4}$ scaling, requiring higher inhibitor dose concentrations for corresponding increase in metals concentrations. Other metals like copper, manganese and zinc were not as detrimental.

\section{References}

[1] J. M. Casas, F. Alvarez, L. Cifuentes, "Aqueous speciation of sulfuric acid-cupric sulfate solutions," Chemical Engineering Science, vol. 55, pp. 6223-6234, 2000.

[2] S. Chesters, M. Armstrong, D. Golding, H. Ostovar, "Cost saving case study using a calcium sulphate specific antiscalant" IDA World Congress, UAE - IDAWC/DB09-269.

[3] A. Rahardianto, "Diagnostic charachterization of gypsum scale formation," Journal of membrane Science, vol. 279, pp. 655-668, 2006.

[4] E. G. Darton, "Membrane chemical research: centuries apart," Membranes in Drinking and Industrial Water Production Proceedings, vol. 2, pp. $161-171$.

[5] D. Shen, D. Shcolnik, R. Perkins, G. Taylor, M. Brown, B. Hughes, "Evaluation of Scale Inhibitors in Marcellus HighIron Waters," Society of Petroleum Engineers, 2012.

[6] C. Gabelich, F. Gerringer, J. Franklin, J. Gao, Y. Cohen, "Reverse Osmosis Pretreatment Challenges With Conventional Treatment," AWWA Annual Conference \& Exposition, 2004.

[7] G. Lefèvre, "In-situ FTIR studies of Inorganic ions adsorption on metal oxides and Hydroxides," Centre d'Etudes de Chimie Métallurgique CNRS-UPR 2801.

[8] Gypsum growth in the presence of growth inhibitors:A scanning force microscopy study, D. Bosbach, M.F.J. Hochella, Chem. Geol. 132 (1996),pp. 227-236.

[9] W.-Y. Shih, A. Rahardianto, R.-W. Lee, Y. Cohen, "Morphometric characterization of calcium sulfate dihydrate (gypsum) scale on RO membranes," J. Membr. Sci., vol. 252, p. 253, 2005.

[10] M.Weijnen, G.M. Van Rosmalen, "Adsorption of phosphonates on gypsum crystals," J. Cryst. Growth, vol. $79,1986$.

[11] M.P.C. Weijnen and G.M. van Rosmalen, "The Role of Additives and Impurities in the Crystallization of Gypsum," Industrial Crystallization, vol. 84, pp. 61-66, 1984. 